\title{
Modeling and Analysis of Laminated Composite Structures
}

\author{
Saleh Alsubari \\ Faculty of Science and Technology. Department \\ mathematics, University Hassan II -Mohammedia- \\ Casablanca /20650, Morocco
}

\author{
Hassan Chaffoui \\ Faculty of Science and Technology. Department \\ physics, University Hassan II Mohammedia- \\ Casablanca / 20650, Morocco
}

\begin{abstract}
In this work we propose to study the simple case of a laminated plate, orthotropic, semi-infinite, composed of four layers same thicknesses. The validation of these results are obtained by comparing the values of the arrow and the constraints resulting from numerical calculations by the finite element method in the case of the plane deformations with those obtained by the various theories of the plates. The results obtained are validated starting from the threedimensional solution and by comparison with the other theoretical models. The evaluation of the errors is made by regarding the results by finite elements as reference. To make a comparison between different models of plates and the results of reference obtained by the finite element method, we had presented the results as a summary table and curves.. We noted that the trigonometric model estimates stresses of shear at best. Indeed, the effects edges (Free, embedded or in simple supports) are well described by the trigonometric model.
\end{abstract}

\section{Keywords}

Laminated composite, plates, Finite element, analysis of interlaminar, plate theory.

\section{INTRODUCTION}

Today, laminated composites are increasingly involved in high-performance applications, particularly in vital parts for the aeronautical industry. Thin structures made of composite laminates are increasingly used in the manufacture of structural components. The enhanced strength to weight ratio makes composites especially attractive for aerospace applications. There is always demand to maximize the payload. All the problems posed in this context are constrained approximation problems with constraints on maximum transverse deflection, buckling load, failure load, natural frequency etc.

It is imperative to estimate the constraint quantities accurately for an acceptable optimal design. The design of laminated composite based components requires a detailed analysis of the response of the structure when subjected to external loads.

For the analysis of laminated composite, we have been proposed several plate theories in the literature $[1,8,10,12$, $13,14,15,22]$. Generally, these plate theories are used to obtain certain global response quantities like the buckling load. However, the use of these theories to obtain local response quantities, i.e. point-wise stresses; interlaminar stresses and strains, can lead to significant errors.

In this work we study the case of the laminated plates and we analyze the evolution of the constraints in their elementary layers.We pay an attention particular to their behavior with the interface of the layers and the effects edges. (Kirchhoff, Reissner) [3, 11, 19] and we introduce a goniometrical function into the field of displacements in order to take into account the effects of shearing and to describe the effects edges.The results obtained are validated starting from the three-dimensional solution and by comparison to other theoretical models $[17,18,19]$. We are studying the global behavior of laminate by adapting the conventional tools of calculations of the structures to the elastic behaviour of composite structures Particularly, we are interested in one of current problem of the multi-layer laminated composites which is the analysis of the distribution of the stress fields in the vicinities of the edges and in the interfaces of the layers which exploit a paramount role the mechanical resistance of the laminatesFor the prediction of the mechanical behavior of each layer constituting the laminate.

\section{FRAMEWORK THEORETICAL OF LAMINATED}

Generally, the properties of a laminate (fig. 1) depend on the nature of the constituents of basic, the orientation of fibers and the stack of layers. Each interface is determined to separate two layers of reinforcement and different directions. However, the classical theory of plates which is generally used to investigate this type of structures is poorly suited, when it comes to highlight effects in game at the interfaces of the layers and explain the process of transfer of loads.

We note that the different models of the theory of plates can be obtained by using a limited development of the displacement field in any point of the domain occupied by the plate:

$\vec{U}(M)=\left(U_{i}\right)=\left(u_{i}\left(M_{0}, t\right)+\sum x_{3}^{j} u_{i}^{(j)}\left(M_{0}, t\right)\right)$

$i=1,2,3$ et $j=1,2,3,4, \ldots \mathrm{n}$

$M_{0}\left(x_{1}, x_{2}, 0\right)$ is the projection of the point $M$ in the average plan $\left(O x_{1} x_{2}\right)$.

In the classical theory of Kirchhoff-Love [2, 3], the distorted $\mathrm{A}^{\prime} \mathrm{B}$ ' a segment of the normal to the average plan $\left(0 x_{l} x_{2}\right)$ and a normal line segment to the deformation of the average plan (Fig. 2a). First improvement consists in modifying this theory by introducing the effects of transverse shearing, as in the natural theory of Reissner Mindlin [2, 5, 7, 11, 20 ]. In cases where the scheme of the first degree would be insufficient, it becomes necessary to proceed to the second-order or even in the third order. This is the case theory of the third order developed by Reddy $[3,4,6,9,10,16,21,23]$ in which the displacement field takes into consideration the warping of the transverse segment during deformation of the plate (Fig. 2c). 


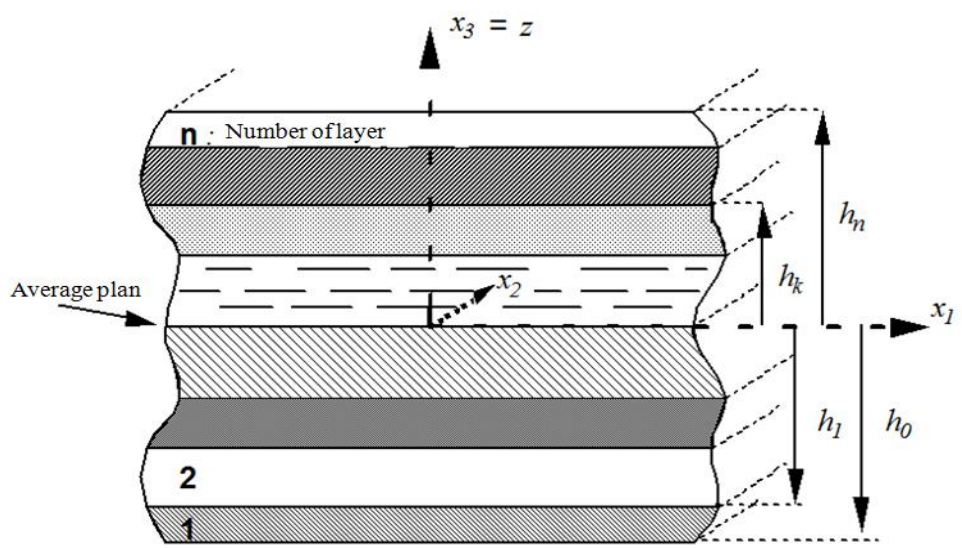

Fig 1: Multilayer geometry of stratified.

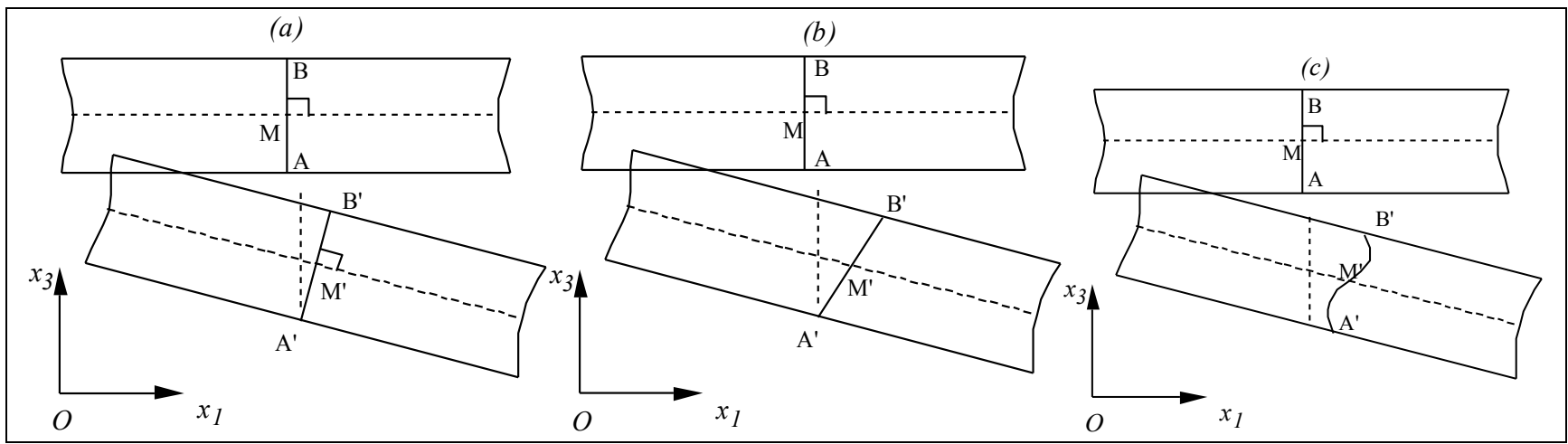

Fig 2: Different types of deformation scheme; (a) Kirchhoff scheme; (b) Reissner scheme; (c) scheme theory refined with consideration of warping.

\section{PROPOSED MODEL}

We propose to introduce a function $\mathrm{g}(\mathrm{x})$ the displacement field, to take into account the effects of shear. By writing the displacement field as:

$u_{i}\left(x_{1}, x_{2}, x_{3}\right)=v_{i}\left(x_{1}, x_{2}\right)-x_{3} \frac{\partial w}{\partial x_{i}}+g\left(x_{3}\right) \cdot \gamma_{i}\left(x_{1}, x_{2}\right)$

$u_{3}\left(x_{1}, x_{2}\right)=w\left(x_{1}, x_{2}\right) \quad i=1,2$

where, $\gamma_{i}=\frac{\partial w}{\partial x_{i}}+\theta_{i},\left(x_{1}, x_{2}\right) \in \Omega$

and $x_{3} \in\left[-\frac{h}{2},+\frac{h}{2}\right]=I_{h}$

$v_{i}$ means the displacement of membrane, $w$ the arrow and $\gamma_{i}$ shear of deformation in the direction $i$ taking into account the potential biases of normal during the deformation of the plate.

The proposed model has the advantage of grouping the different types of plates under a single write. Thus, we find the model Kirchhoff-Love for $\mathrm{g}\left(\mathrm{x}_{3}\right)=0$, that of ReissnerMindlin for $\mathrm{g}\left(\boldsymbol{x}_{3}\right)=\boldsymbol{x}_{3}$ and Reddy for $g\left(x_{3}\right)=x_{3}\left(1-4 x_{3}^{2} / 3 h^{2}\right)$. then we give a sinusoidal function $g\left(x_{3}\right)$ a $f$ sinusoidal form: $g\left(x_{3}\right)=\frac{h}{\pi} \sin \left(\frac{\pi x_{3}}{h}\right)[4]$

\section{THE BEHAVIOR OF LAW}

Using the law of elastic behavior $\sigma_{i j}=c_{i j k h} \varepsilon_{k h} \mathrm{i}, j, \mathrm{k}, h=1,2,3$ and, applying the principle of virtual power and all the boundary conditions of the borders, we obtain relations efforts that are written in the generalized form:

$N_{i j}=A_{i j k h} \frac{\partial v_{k}}{\partial x_{h}}-D_{i j k h} \frac{\partial^{2} w}{\partial x_{k} \partial x_{h}}+\tilde{D}_{i j k h} \frac{\partial \gamma_{k}}{\partial x_{h}}$

$M_{i j}=D_{i j k h} \frac{\partial v_{k}}{\partial x_{h}}-B_{i j k h} \frac{\partial^{2} w}{\partial x_{k} \partial x_{h}}+b_{i j k h} \frac{\partial \gamma_{k}}{\partial x_{h}}$

$\tilde{M}_{i j}=\tilde{D}_{i j k h} \frac{\partial v_{k}}{\partial x_{h}}-b_{i j k h} \frac{\partial w}{\partial x_{k} \partial x_{h}}+\tilde{B}_{i j k h} \frac{\partial \gamma_{k}}{\partial x_{h}}$

$\tilde{Q}_{i}=\tilde{A}_{i 3 j 3} \gamma_{j} \quad i, j, k, h=1,2$

$M_{i j}=\int_{I_{h}} x_{3} \sigma_{i j} d x_{3}, \tilde{M}_{i j}=\int_{I_{h}} g\left(x_{3}\right) \sigma_{i j} d x_{3}$

and $\tilde{Q}_{i 3}=\int_{I_{h}} g^{\prime}\left(x_{3}\right) \sigma_{i 3} d x_{3}$ 


$$
\begin{aligned}
& \left(B_{i j k h}, b_{i j k h}, \tilde{B}_{i j k h}\right) \\
& =\int_{I_{h}} C_{i j k h}^{\prime}\left(x_{3}^{2}, \mathrm{x}_{3} g\left(x_{3}\right),\left(g\left(x_{3}\right)\right)^{2}\right) d x_{3} \\
& \left(D_{i j k h}, \tilde{D}_{i j k h}\right)=\int_{I_{h}} C_{i j k h}^{\prime}\left(x_{3}, g\left(x_{3}\right)\right) d x_{3} \\
& \text { and }\left(A_{i j k h}, \tilde{A}_{i 3 j 3}\right)=\int_{I_{h}}\left(C_{i j k h}^{\prime}, C_{i 3 j 3}\left(g^{\prime}\left(x_{3}\right)\right)^{2}\right) d x_{3}
\end{aligned}
$$

- $N_{i j}, M_{i j}$ are respectively the efforts of the membrane and the moments of the classical theory of plates (Kirchhoff-Love and Reissner) and $\tilde{M}_{i j}, \tilde{Q}_{i}$ are the moments and shear forces of the theory refined to a function with the polynomial associated with a degree greater than one.

\section{EQUILIBRIUM EQUATIONS}

By neglecting the effects of membrane $\left(v_{i}=0\right)$, the equilibrium of equations are general form as follows:

$$
\begin{aligned}
& -B_{i j k h} \frac{\partial^{4} w}{\partial x_{i} \partial x_{j} \partial x_{k} \partial x_{h}}+b_{i j k h} \frac{\partial^{3} \gamma_{k}}{\partial x_{i} \partial x_{j} \partial x_{h}}+q_{3}=0 \\
& -b_{i j k h} \frac{\partial^{3} w}{\partial x_{j} \partial x_{k} \partial x_{h}}+\tilde{B}_{i j k h} \frac{\partial^{2} \gamma_{k}}{\partial x_{j} \partial x_{h}}-\tilde{A}_{i 3 j 3} \gamma_{j}=0
\end{aligned}
$$

The natural boundary conditions are written in their generalized form:

$$
\begin{aligned}
& \frac{\partial}{\partial s}\left(M_{i j} n_{i} m_{j}\right)+\frac{\partial M_{i j}}{\partial x_{i}} n_{j}=T_{3}, N_{i j} n_{j}=T_{i}, \\
& M_{i j} n_{i} n_{j}=M_{f}, \tilde{M}_{i j} n_{j}=C_{i}, \gamma_{i}=0, w=0
\end{aligned}
$$

$T_{i}$ efforts are the lineiques.on the edges of the plate, $n_{i}$ and $m_{i}$ are respectively the components of the vectors tangent and normal to the contour of the plate and $M_{f} C_{i}$ are the moments lineiques.

\section{APPLICATIONS}

We propose to study the simple case of a plate laminated orthotropic semi-infinite, consisting of four layers of the same thicknesses oriented $\left(90^{\circ} / 0^{\circ} / 0^{\circ} / 90^{\circ}\right)$, built on the side $x_{l}=0$, free on the end $x_{1}=\mathrm{L}$ and supporting a transverse load $\left(\mathrm{q}=10^{4} \mathrm{~Pa}\right.$ ) uniformly distributed over the upper surface (Fig. 4). The validation of these results is obtained by comparing the values of the arrow and constraints from numerical calculations by the finite element method in the case of plane strain to those obtained by the different theories of plates. The error evaluation is made by considering the finite element results as a reference. The finite element mesh (Fig. 4.c), based on the choice of eight-node quadrilateral elements, is carried out in the cross section $\left(x_{1}, x_{2}\right)$.

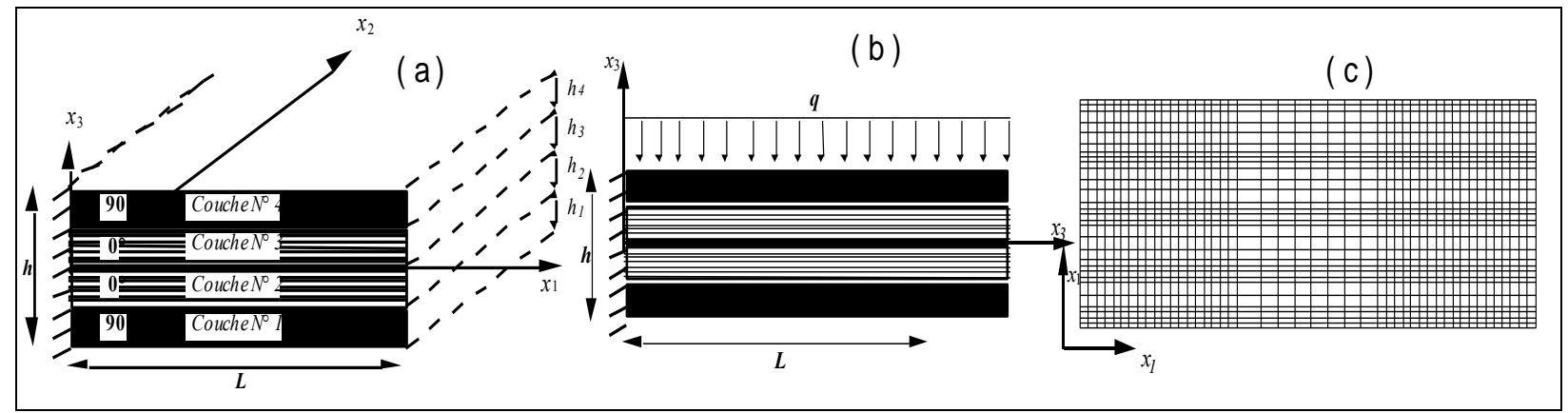

Fig 3: (a) Schematic of the laminate studied, (b) Useful section of the plate, (c) Finite element mesh. Geometrical parameters: $\mathrm{L}=7.57 \mathrm{~m}, \mathrm{~h} / \mathrm{L}=\mathbf{0 . 3 7}, \mathrm{h}_{1}=\mathrm{h}_{2}=\mathrm{h}_{3}=\mathbf{h}_{4}$. Mechanical parameters (unit GPa) $\mathbf{E}_{\mathrm{L}}=242, \mathbf{E}_{\mathrm{T}}=19, \mathrm{G}_{\mathrm{LT}}=\mathbf{5 . 2}, \mathrm{G}_{\mathrm{TT}}=3.5, \mathrm{v}_{\mathrm{LT}}=\mathbf{0 . 2 4}$ and $v_{\mathrm{TT}}=\mathbf{0 . 2 5}$.

To make a comparison between the different models of plates and the reference results obtained by the finite element method, we have presented results as a summary table and curves. Table I shows the main results for the numerical values maximum of the arrow and constraints rescaled using the following relations: $\bar{\sigma}_{i j}\left(x_{1}, x_{3}\right)=\sigma_{i j}\left(x_{1}, x_{3}\right) / q$ and $\bar{w}\left(x_{1}, x_{3}\right)=100 . w\left(x_{1}, x_{3}\right) / h$ where $q$ is the uniformly distributed load.

We note that the effects of shear are very important and can't be neglected in the vicinities of the edges. On the other hand, if the constraints $\sigma_{11}$ from the theory of Kirchhoff-Love remains an acceptable approximation, the arrow $w$ due to shear is such that these values should be taken with caution when it comes to estimating the arrow at the free edge.
Table 1. Maximum values rescaled "displacement and stress

\begin{tabular}{|l|c|c|c|}
\cline { 2 - 4 } \multicolumn{1}{c|}{} & $\bar{w}(L) 10^{-4}$ & $\bar{\sigma}_{11}(h, h / 4)$ & $\bar{\sigma}_{13}(h, 0)$ \\
\hline Kirchhoff Love & 0.851 & 33.99 & \\
\hline Reissner & 1.389 & 33.99 & 3.47 \\
\hline Reddy & 1.596 & 31.99 & 3.96 \\
\hline Sinus & 1.634 & 32.29 & 4.47 \\
\hline F.E.M & 1.677 & 32.99 & 4.88 \\
\hline
\end{tabular}



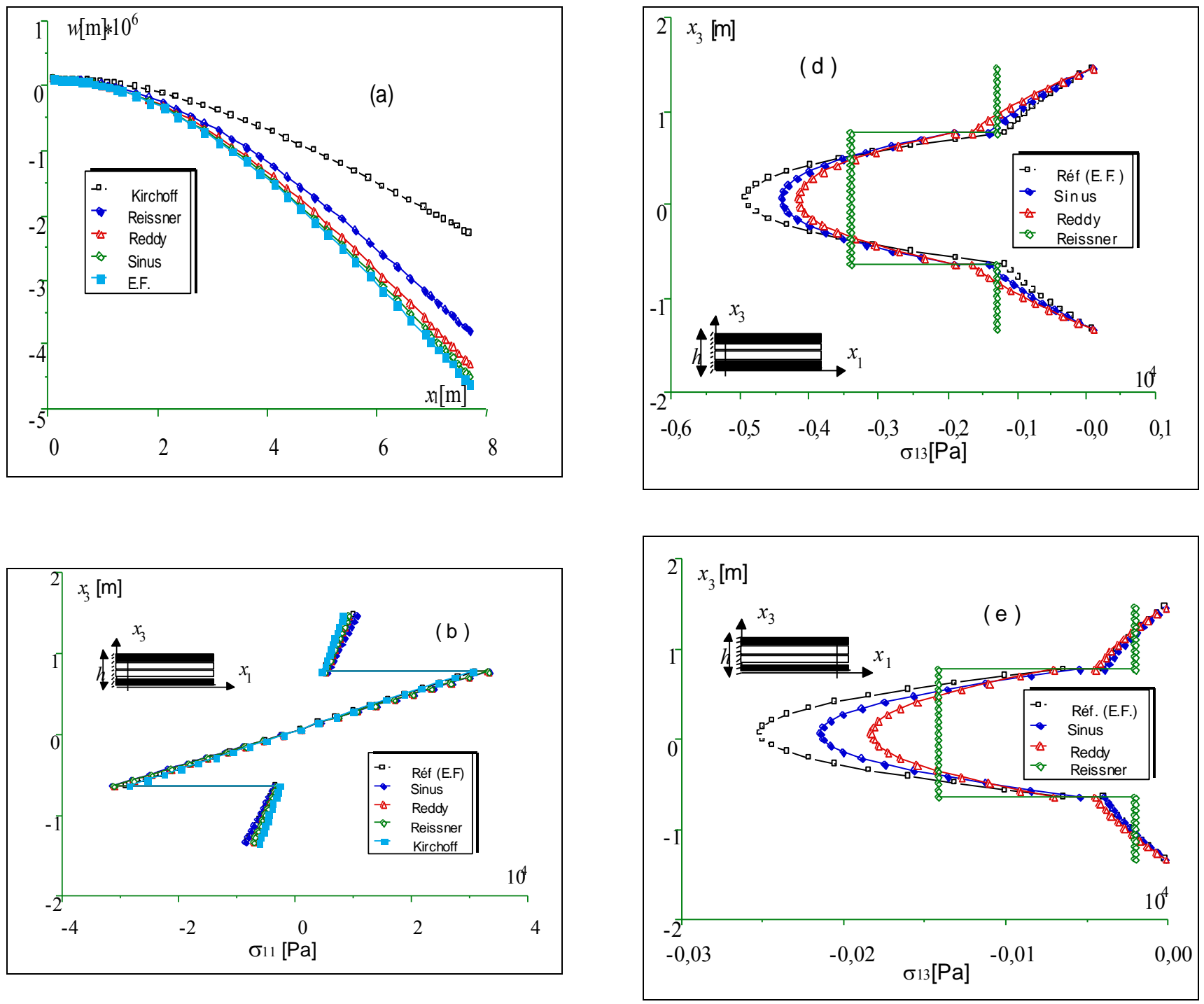

Fig 4: a. Evolution of the arrow of the average plan laminate.

b. constraints $\sigma_{11}\left(\mathrm{~h}, x_{3}\right)$ in function of $x_{3}$, (Unit : [Pa]) c. constraints $\sigma_{11}\left(\mathrm{~L}-\mathrm{h}, x_{3}\right)$ in function of $x_{3}$; (Unit : [Pa]), d. constraints $\sigma_{13}\left(\mathrm{~h}, x_{3}\right)$ in function of $x_{3}$, (Unit: [Pa]) e. constraints $\sigma_{13}\left(\mathrm{~L}-\mathrm{h}, x_{3}\right)$ in function of $x$,(Unit : [Pa]). 


\section{CONCLUSION}

In this study the results obtained are validated starting from the three-dimensional solution and by comparison with the other ideal models. The validation of these results is obtained by comparing the values of the arrow and constraints from numerical calculations by the finite element method in the case of plane strain to those obtained by the different theories of the plates. While referring to the three-dimensional solution, we note that the trigonometric model estimates stresses of shear at best. Indeed, the effects edges (Free, embedded or in simple supports) are well described by the trigonometric model.

The results obtained shows that the trigonometric model can be a very economic modeling tool in the case of thick plates, used in civil engineering.

\section{REFERENCES}

[1] M. Karama, M. Touratier, A. Idilbi, An evaluation of Edge Solution for A Higher-Ordre Laminated Plate Theory, Composite Structures, 1993, 25, pp. 495-502.

[2] G. Kirchhof, Über das gleichgewicht und die bewegung einer elastischen scheibe, J. Angew. Math. 1850, pp. 4041.

[3] P. Ladevèze, Une nouvelle version de la théorie des plaque de Kirchhoff-Love, C. R.Acad. Sci. Paris, T. 312, Série II, 1991, pp. 151-156.

[4] K. H. Lo, R. M. Christensen, E.M. Wu, A Higher-Order Theory of Plate Deformation, ASME J. App. Mech., V. 18, 1977, December, pp. 663-676.

[5] Ji-Fan $\mathrm{He}$ et al, Bending analysis of laminated plates using a rafined shear deformation theory, Composite Structures 24, 1993, pp. 125-138.

[6] X.L. Fan1, Q. Sun, M. Kikuchi Review of Damage Tolerant Analysis of Laminated Composites. Journal of Solid Mechanics Vol. 2, No. 3 (2010) pp. 275-289.

[7] R. D. Mindlin, Influence of rotatory inertia and shear on flexural motions of isotropic, elastic plates, J. Appl. Mech., 1951, Vol. 18, pp. 31-38.

[8] P.M. Mohite, C.S. Upadhyay, Region-by-region modeling of laminated composite plates. Elsevier Computers and Structures 85 (2007) 1808-1827.

[9] N.J. Pagano, Exact Solutions for Rectangular bidirectionnal Composites and Sandwitche plates, J. of Comp. Mater. 1970, Vol. 4, pp 20-34.

[10] J. N. Reddy, A Simple higher - order theory of laminated Composite Plate, J. App. Mech., 1984 December, pp. 745-752.
[11] E. Reissner, The effect of transverse shear deformation on the bending of elastic plates, J. Appl. Mech., 1945, Vol. 12, pp. A69-A77.

[12] S. Alsubari, H. Chaffoui. Study of the Mechanical Behavior of Composite Plates by Homogenisation. Elsevier. Procedia Engineering 15 (2011),pp 4063 4067.

[13] Tatiane Corrêa de Godoy, Marcelo Areias Trindade Modeling and analysis of laminate composite plates with embedded active-passive piezoelectric networks: Paper published in Journal of Sound and Vibration, 330(2):194216, 2011.

[14] M. Touratier, Un modèle simple et efficace en mécanique des structures composites, C. R. Acad. Sci. Paris, T. 309, Série II, 1989, pp. 933-938.

[15] M. Touratier, A efficient standard plate theory, Int. J. Engng. Sci. ,29, Nº , pp 901-916,1991.

[16] J. M. Whitney, Stress analyis of thick laminated composite and sandwitch plates, J. of. App. Mech. 1972, Vol.6, pp.426-440.

[17] S. Sriniva, A. K. Rao, Flexure of thick rectangular plates, J. of App. Mech., March 1973, pp. 298-299.

[18] S. Srinivas, A. K Rao, Bending, vibration and buckling of simply supported thik orthotropic rectangular plates and laminates, Int. J. Solids and Structures, V. 6, 1970, pp. 1463-1481.

[19] P. Ladevèze, F. Pécastaings, The optimal Version of Reissner's theory, J. App. Mech., V. 55, June 1988, pp. 413-418.

[20] S. Vlachoustis, Shear correction factors for plates and shells, Int. J. for Num. Meth. In Engng. Sci., 33, $\mathrm{N}^{\circ} 8$, 1991, pp. 901-916.

[21] J. M. Whitney, The effect of transverse shear deformation on the bending of laminate plates, J. Comp. Mat., V. 3, 1969, pp. 534-547.

[22] H. Chaffoui, M. EL Hammouti, A. Yeznasni, R. EL Guerjouma, Modélisation et analyse du comportement mécanique des structures composites stratifiées, $4^{\text {èmes }}$ Journées Maghrébines d'Etudes de Génie Mécanique, 28 - 30 Novembre 1999, Constantine, Algérie.

[23] He Ling-Hui, A linear theory of laminated shells accounting for continuity of displacements and transverse Shear Stress at layer Interfaces, Int. J. Solides Structures, V. 31, $\mathrm{N}^{\circ}$ 5, 1994, pp. 613-627. 